\title{
JUBILEE OF THE UNIVERSITY OF BIRMINGHAM
}

\author{
By Dr. MARTIN JOHNSON
}

\begin{abstract}
$\mathrm{O}$ N May 4-5 the University of Birmingham celebrates the half-century since its emergence from the Mason University College, and some survey of its achievements and prospects is appropriate, particularly in the scientific field. In emphasizing in Nature the scientific departments, it is worth remem. bering that even the original Mason College catered for all studies (except theology, banned until the present generation), although the three main streams feeding into it were undoubtedly scientific, technical and medical. It is a healthy sign of balance that to-day many in Britain or abroad think of the University of Birmingham primarily as the fortunate possessor of the Barber Institute of Fine Arts, where paintings by Rembrandt, Rubens, Tintoretto, Murillo, Gainsborough, Corot and Monet may be seen, with ancient Egyptian, Chinese, Persian, Greek and modern sculpture, and where music is performed by the world's greatest artists when they visit England; the situation of this unique gallery within a few yards of the physics laboratories may be a symbol that this University is not one-sided, a symbol made real when the large proportion of scientific workers among the Barber audiences is noticed.
\end{abstract}

Another achievement in balance is the association and co-operation between fundamental and applied sciences. Pure mathematics had flourished for a generation under Prof. G. N. Watson, but only just before the Second World War was a Department of Mathematical Physics created, under Prof. R. E: Peierls, around whom are now gathered researchers from half a dozen European countries, from the United States and from the Dominions. The harnessing of this Department with the larger team of experimental physicists under Prof. M. L. Oliphant led to vital contributions by this University to the war needs: the cavity magnetron, described by responsible American opinion as "the most valuable of all reversed lease-lend", was devised in the Birmingham laboratory, before the team migrated overseas to carry out the atomic plans which Peierls himself had been creating in Birmingham, and to which the local work of the late Sir Norman Haworth had contributed the chemical developments. Since the War the largest item in Birmingham physics has been the completion of the 300-ton cyclotron, and the early stages of the 800 -ton proton symchrotron, though the laboratory is not confined to nuclear research; in fact, luminescence of the solid state, dielectrics, experimental gas kinetics and biophysical and astronomical topics are also under investigation, quite apart from the separate flourishing Department of Electron Physics under Prof. J. Sayers. The long and distinguished tenure of the chemistry chair by the late Sir Norman Haworth yielded a great school of research in carbohydrates and vitamins, among other names in which have been Prof. E. L. Hirst (now of the University of Edinburgh), Prof. S. Peat (now of the University College of North Wales) and Prof. M. Stacey, who is still in Birmingham as head of the organic chemistry side. In the last few years the Chemistry Department has developed another large-scale enterprise, this time in physical chemistry, under Haworth's successor, Prof. H. W. Melville.

In the biological sciences, apart from medicine, Prof. W. Stiles in botany, a succession in zoology including Profs. H. Munro Fox, Lancelot Hogben, and now P. B. Medawar, who is also dean of the Faculty of Science, have initiated research schools to which there is recently added the genetics laboratory under Prof. K. Mather. Geology has always been a ljve subject of Birmingham research, as well as of auxiliary teaching to mining and engineering students, ever since the pioneer days of Lapworth, while a rapidly expanding Department of Geography, including meteorology and modern methods of regional survey, serves the Faculties of Arts and Cømmerce as well as Science. It is natural that, in its Midland situation, the University should be looked to for fundamental research and teaching in metallurgy, in addition to the more universal topics of mechanical, civil and electrical engineering, and under Prof. D. Hanson the Department of Metallurgy now includes three other chairs and a large research staff, divided into teams working on physical, electronic, and atomic aspects of the metallic state, and a separate organisation for industrial metallurgy in close touch with the manufacturing world. In the earlier days under Sir John Cadman, mining and oil technology were already attracting students to Birmingham from all over the world; this work is now organised under a professor of mining and two of chemical engineering, each with international recruitment of research groups.

The University Medical School had grown out of a nineteenth-century college and the individual teach. ing of some famous pioneer surgeons at the great Birmingham hospitals. Its present position in the forefront of British medical education owes much to the enterprise of the 1930's in building a large ultramodern teaching hospital adjacent to the University, a plan developed through the vision and indefatigable labours of Stanley Barnes, the great neurologist, Sir Charles Grant Robertson, and Sir Harry Vincent. It would be.invidious to pick out particular departments in a school whose glory is its uniform excellence; but one should mention in clinical studies the Children's Hospital developed by Sir Leonard Parsons, who is still dean of medicine, and the Dental School under Col. H. F. Humphreys, who is now vice-principal of the University. In pre-clinical work, the great research teams under Zuckerman (anatomy), and under Gilding (physiology) and Frazer (pharmacology), would make the place famous even if there were no others.

In the last twenty years a large Faculty of Commerce and Social Science, under Prof. Sargant Florence and a brilliant corps including Americans and Russians, has grown out of the Economic and Regional Industrial Department created by Sir William Ashley and Prof. J. G. Smith, sometime vice-principal of the University. Its interest in the human as well as the economic owes much to the Birmingham philosophers, Muirhead and later Russell, 
who regarded social ethics as the livest of topics. The Faculty has become the recognized consultant and training ground on all matters, local and national, of industrial administration.

Another organisation also recently outgrowing its ancestry is the Institute of Education under Prof. M. V. C. Jeffreys, the research centre to which look the training colleges and education authorities of the Midland counties. The most widespread of these extensions of University influence outside its walls is the Extra-Mural Department, under D. R. Dudley, who controls many part-time and full-time tutors of hundreds of classes throughout the Midland counties : a feature distinguishing this from the earlier Workers' Educational Association and 'university extension classes' is the inclusion at a high level of specialist postgraduate courses and residential week-ends serving as refresher courses to professional men and women who feel in danger of losing touch with the rapid growth of their subjects since student days.

The welding of all these enterprises, many completely new in this generation, into a loyal and friendly community is due to the personality of the present vice-chancellor, Sir Raymond Priestley. Besides the more usually recognized academic duties, he has made a unique place in modern university administration by his constant and shrewd understanding of undergraduate life and feeling; although maintaining closer touch with students than most academic heads, he has insisted on student autonomy in the managing of their own buildings and laws and finances, to an extent not known elsewhere. He has also created the Department of Physical Education. Under its head, A. D. Munrow, the staff of this includes men and women of international fame as athletes who are moreover distinguished for their wisdom and insight into student needs. There are two full-time medical officers, available to the whole University, and there is a highly organised office of the Lodgings Warden; it is no longer possible to reproach the provincial university, so far as Birmingham is concerned, with caring little what happens to the student outside of class and exam. ination.

The barrier now obstructing Birmingham's full utilization of these expanding schemes is lack of buildings : it has residential halls for not more than three hundred of its 3,500 students, and even the teaching in arts and law remains in the outworn building which was Mason College in the city centre. Before the War the rehousing of these faculties alongside the great scientific and medical buildings at Edgbaston, three miles out, was about to begin, and there is land in plenty on the site; but in a city where 100,000 buildings were bomb-damaged and where 40,000 families await domestic rehousing, it is obvious that licences and materials for such largescale academic construction are bound to be drastically in arrear. In fact, small additions to the buildings for medicine and physics, and the rebuilding of those for mechanical and electrical engineering and industrial metallurgy, are the only walls now new. But the problem is not only "How can a government assign priorities ahead of housing ?", and the Midlands are also beginning to ask, "Can the community afford to delay longer the unifying of a great academic centre on a single site, the fusing of all faculties into that common mind of scholarship without which the University's service to the public is crippled ?"

\section{THE SCINTILLATION OF STARS}

TN two recent communications ${ }^{1}$, Prof. H. Hartridge 1 expresses doubt about the physical explanation of the scintillation of stars. Now these phenomena have been extensively studied in a series of classical papers which are reviewed and summarized in $\mathbf{6 3}$ pages of Pernter-Exner's "Meteorologische Optik" (Wien, 1922), or in Danjon's "Lunettes et Télescopes" (Paris, 1935), and there would be little point in repeating explanations so well established. The observations which Prof. Hartridge requires as a test have already been made and fully confirm the physical theory.

(1) Movements of the star images at right-angles to the line of sight are not visible to the naked eye because they are too small, but they are known to every astronomer. They have been recorded as a function of time by Schlesinger ${ }^{2}$ and by other authors, and are found to be of the order of a few seconds of arc.

(2) Prof. Hartridge expects that these star movements should take place preferentially in the direction of the wind. This is a misapprehension; the striæ follow the wind, but the refraction is at random. This motion of the stria is evidenced by the undulations at the limb of the sun and by photographic records ${ }^{3}$.

(3) Prof. Hartridge expects that owing to sointillation the star images would be drawn out into spectra. This is a widespread misconception. The displacement of the star being so small, an additional dispersion effect would be wholly unobservable. The origin of the coloured scintillation is the regular atmospheric refraction, due to which a green ray and a red ray of the star travel at an increasing distance from each other, and so pass through different striæ and scintillate independently. Very interesting spectral phenomena of the scintillation, noted by Respighi, are slightly more complicated but can be satisfactorily explained.

(4) A comparison between the scintillation as observed by the right and by the left eye is very difficult, and requires a great deal of practice. R. W. Wood was able to observe the difference between the scintillation for the left and for the right eye, which proves that most striæ are smaller than $7 \mathrm{~cm}$.

(5) A stereoscopio effect cannot be expected (a) because the lateral displacements are unobservable with the naked eye anyway; (b) because the phenomenon is much too rapid to permit of binocular adjustment.

(6) Prof. Hartridge does not see how the physical theory could explain the observed variations in brightness. These variations in brightness are due to variations in the convergency or divergency of the rays; it can be shown quantitatively that the small changes in direction may cause considerable variations in brightness. These variations have been recorded on a photographic plate ${ }^{3}$ and may be demonstrated with a photocell and a cathode ray oscillograph. I wonder how physiology would explain the striking difference in scintillation between stars at high and at low altitude above the horizon.

As to physiological phenomena, I would not like to reject them altogether. It is said that stars are seen to scintillate somewhat more in the twilight; also, that reddish stars seem to scintillate more than 